\title{
A ELABORAÇÃO CONCEITUAL EM ALUNOS COM DEFICIÊNCIA INTELECTUAL: APONTAMENTOS A PARTIR DAS PROVAS DE LURIA
}

Roberta Pires ${ }^{\mathrm{i}}$

\begin{abstract}
Resumo: O presente artigo tem como objetivo apresentar reflexões sobre a elaboração de conceitos em alunos com deficiência intelectual a partir das indicações do método de investigação de conceitos de Luria. A investigação é um recorte da dissertação de mestrado concluída, vinculada ao "Observatório de Educação Especial e Inclusão Educacional (ObEE)“ fundamentada na perspectiva histórico-cultural. Realizada numa escola municipal localizada na Baixada Fluminense a partir dos pressupostos do estudo de caso qualitativo. Como instrumentos de coleta de dados utilizamos as indicações do método de investigação de conceitos de Luria. Evidenciamos que a relação de ensino e aprendizagem deste alunado, que foge do modelo de "aluno ideal", está calcada em práticas pedagógicas a eles dirigidas, que, muitas vezes, são esvaziadas de sentidos, oportunizando menos experiências de aprendizagem e ofertando menos possibilidades de desenvolvimento. Nessa direção, os resultados indicaram que muitos alunos pouco participam das atividades. Mas, também revelam as possibilidades e os caminhos a serem seguidos para que estes alunos tenham acesso aos conhecimentos historicamente construídos.
\end{abstract}

Palavras-chave: Formação de conceitos, deficiência intelectual; processos de ensino e aprendizagem.

\section{THE CONCEPTUAL PRACTICE IN STUDENTS WITH INTELLECTUAL DEFICIENCY: NOTES FROM THE LURIA'S TESTS}

\begin{abstract}
The present article aims to present reflections on the elaboration of concepts in students with intellectual disabilities from the indications of the method of investigation of concepts of Luria. The research is a cut of the master's dissertation completed, linked to the "Observatório de Educação Especial e Inclusão Educacional (ObEE)" based on the historicalcultural perspective. Carried out in a municipal school located in the Baixada Fluminense from the assumptions of the qualitative case study. As data collection instruments we use the indications of the method of investigation of concepts of Luria. We show that the teaching and learning relationship of this students, who escapes from the "ideal student" model, is based on pedagogical practices addressed to them, which are often emptied of meaning, giving less learning experiences and offering less possibilities for development. In this direction, the results indicated that many students do not participate in the activities. But also reveal the possibilities and paths to follow to allow these students have access to knowledge historically constructed.
\end{abstract}

Keywords: Concept formation, intellectual disability; teaching and learning processes. 


\section{Introdução}

Ao pensarmos na escolarização de alunos com deficiência intelectual é necessário ter clareza que, muitas vezes, esses alunos em função de suas especificidades necessitam de recursos alternativos e práticas pedagógicas mediadas para que haja construção de conceitos científicos no espaço escolar. Para Corrêa e Moraes (2015) o foco é naquilo que a pessoa com deficiência é capaz de fazer e não no seu comprometimento orgânico. Mas como desenvolver tais habilidades nos educandos e em especial nos alunos com deficiência intelectual se a escola está cada vez mais ofertando menos a este alunado? Os conceitos científicos que a escola deve ensinar são molas propulsoras para a compreensão da realidade que levará a uma educação para a autonomia. A tarefa da escola é ofertar condições para que todos os alunos construam formas mais elaboradas de pensamento, saindo dos conceitos cotidianos e avançando para os conceitos científicos que são próprios do espaço escolar. Os conceitos cotidianos também chamados de espontâneos são adquiridos na vivência diária e nas experiências práticas, ou seja, em situações informais de aprendizagem (VIGOTSKI, 2010). Para Friedrich (2012) os conceitos cotidianos relacionam-se com as coisas do mundo. Os conceitos científicos, que são próprios do espaço escolar, diferem dos cotidianos por serem generalizações de segunda ordem, pois sua relação com o mundo é feita sempre por intermédio de outro conceito.

O processo da elaboração conceitual em alunos com deficiência intelectual ocorre a partir do constante processo de mediação pedagógica, que se realiza através da interação entre os indivíduos, professor/aluno e/ou aluno/aluno, o que envolve o desenvolvimento das funções psicológicas superiores, as quais, para Vigotski (2000) se originam das relações humanas e das trocas coletivas. Para Pino (2000) o outro é a condição para o desenvolvimento.

Com base nesse pressuposto este artigo discute a partir da perspectiva histórico-cultural como ocorre a elaboração de conceitos em alunos com deficiência intelectual a partir das indicações do método de investigação de Luria, doravante chamado de provas do Luria (1986) que nos fornecem indícios de como o pensamento se organiza pela palavra no processo da elaboração de conceitos. Este estudo de caso foi realizado com dois alunos com deficiência intelectual que frequentam classes comuns de ensino, séries iniciais, em duas escolas no Município de Belford Roxo, localizado na Baixada Fluminense, Estado do Rio de Janeiro/Brasil. 


\section{Metodologia}

O cotidiano escolar nos remete a uma abordagem que contemple a dinâmica da escola e os sujeitos participantes. Optamos por utilizar o estudo de caso de cunho qualitativo pela possibilidade de descrever e interpretar os dados de maneira reflexiva tendo uma cartografia do cotidiano escolar. Para Yin (2005, p. 24) é uma metodologia válida, conforme podemos ver, nas situações em que as questões a serem respondidas são do tipo “como?” ou “por que?”, quando o pesquisador se encontra em fenômenos complexos e contemporâneos, inseridos no contexto da vida real. Deste modo, o "como" se refere de que forma os mecanismos mentais funcionam para a construção dos conceitos científicos e "como" a escola está contribuindo para este desenvolvimento. Como instrumento de análise utilizamos as indicações do método de investigação de conceitos do Luria (1986), denominada provas de Luria, nas salas de Recursos Multifuncionais (SRM).

As ações junto aos sujeitos foram realizadas em momentos e dias distintos em escolas públicas no Município de Belford Roxo, localizado na Baixada Fluminense, Estado do Rio de Janeiro/Brasil. O município de Belford Roxo compõe a região da Baixada Fluminense, no estado do Rio de Janeiro, formada por treze municípios que ficam nas proximidades da rodovia BR116, Rio-São Paulo, e provida por uma malha ferroviária que leva milhares de trabalhadores a outros bairros e cidades da região metropolitana do Rio de Janeiro. É um lugar com pouca infraestrutura em relação a urbanização, saneamento básico, entre outras questões sociais. A economia é local, destacando-se algumas indústrias do ramo químico como a Bayer do Brasil, Termolite e a Lubrizol. Grande parte da população não trabalha no município que reside, conforme Monteiro e Pletsch (2014) esclarecem, Belford Roxo é considerada uma cidadedormitório, em que uma grande massa de trabalhadores se desloca para trabalhar, principalmente no município do Rio de Janeiro.

Nossos sujeitos de pesquisa são dois alunos (André e Júlio) com deficiência intelectual frequentam os anos inicias e a Sala de Recursos Multifuncionais com Atendimento Educacional Especializado. Os nomes apresentados são fictícios, preservando a imagem dos sujeitos. 
Quadro 1 - Caracterização dos sujeitos da pesquisa

\begin{tabular}{|c|c|c|c|c|}
\hline NOME & IDADE & SEXO & $\begin{array}{c}\text { ANO DE } \\
\text { ESCOLARIDADE }\end{array}$ & DIAGNÓSTICO \\
\hline Júlio & 8 anos & M & $2^{\circ}$ ano & $\begin{array}{c}\text { Deficiência } \\
\text { intelectual }\end{array}$ \\
\hline André & 8 anos & M & $3^{\circ}$ ano & $\begin{array}{c}\text { Deficiência } \\
\text { intelectual }\end{array}$ \\
\hline
\end{tabular}

Fonte: Banco de dados ObEE (2015).

Apresentamos dezesseis imagens de animais no formato de cartões coloridos, com a dimensão de $10 \mathrm{~cm}$ x $15 \mathrm{~cm}$, que representam diferentes categorias presentes na classificação: peixes, anfíbios, répteis, aves e mamíferos conforme figura a seguir:

Figura 1 - Imagens de animais

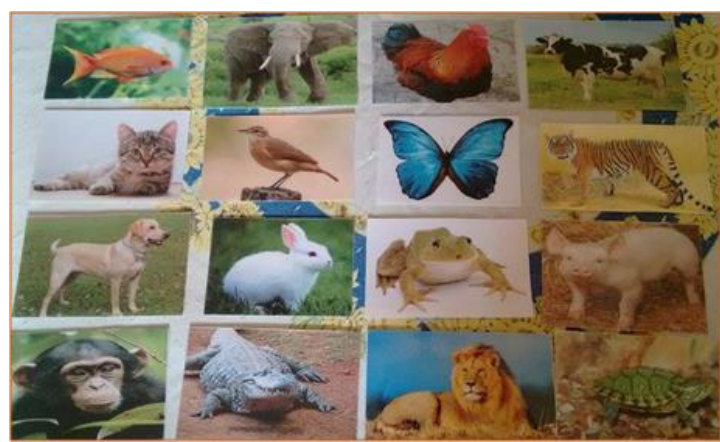

Fonte: Pletsch, Mendes e Hostins (2016)

Ofertamos estas imagens - que foram impressas em alta definição, no formato de cartões, com a dimensão de $10 \mathrm{~cm}$ x $15 \mathrm{~cm}$, em papel colorido - para André e Júlio, individualmente e em dias distintos, com o intuito de analisar em qual etapa da construção de conceitos se encontram, ou seja, como o pensamento se organiza pela palavra no processo de formação de conceitos científicos, pois, "a medida que a criança se desenvolve, mostra-se como se estrutura a consciência, cuja "célula” é a palavra" (LURIA, 1986, p.57). O método de investigação de conceitos de Luria (1986), aplicado na nossa pesquisa, exige dos participantes, que eles avancem de um nível inicial para o mais complexo, conforme o exposto a seguir:

Figura 2 - Etapas do método de investigação de conceitos do Luria 


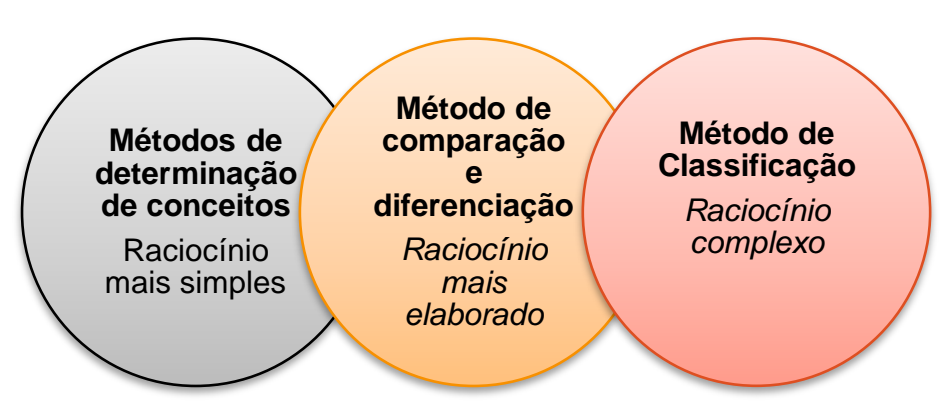

Fonte: Elaborada pela autora a partir de Luria (1986)

O método de determinação de conceitos (LURIA, 1986) que consiste em analisar em qual sistema de enlaces estão os alunos na etapa de seu desenvolvimento infantil. Se os sujeitos ao determinarem o significado de uma palavra estão nas experiências concretas, enlaces reais imediatos, ou categorizando as palavras, inserindo-as no estágio de relações lógico verbais (LURIA, 1986). É o que Vigotski diferenciou como conceitos cotidianos, que são construídos a partir da experiência imediata e os conceitos científicos que categoriza o objeto dentro de um sistema lógico-verbal.

Na sequência realizada com os alunos, demos continuidade com a dinâmica, aplicando o método de comparação e diferenciação (LURIA, 1986), a fim de perceber a relação lógicoverbal de conceitos nos animais apresentados. Esta fase consistiu em apresentar duas imagens ao aluno e, em seguida, foi sugerido que ele separasse os animais em grupos com características semelhantes, isto é, animais que ele considerasse ter algo em comum. Por fim, foi pedido que os diferenciasse, quando foram ofertadas as imagens de dois animais. Luria (1986) esclarece que os adultos facilmente conseguem separar o traço comum necessário e categorizar as duas imagens dentro de uma categoria geral determinada, ou seja, os enlaces são lógico-verbais

E, por último, o método de classificação, que é usado em três vertentes, mas nesta pesquisa, nos deteremos apenas na classificação livre, que corresponde à segunda variante da prova, que adaptamos para a categoria animais. Originalmente foram trabalhados por Luria objetos distintos como: animais, vegetais, móveis, entre outros. Optamos por ofertar as imagens de animais com o objetivo que os alunos os agrupassem por categorias ou por conceitos. A complexidade ou não das respostas nos forneceu subsídios para analisarmos a elaboração conceitual dos sujeitos, partindo do postulado que o conceito deve ser analisado não somente pela palavra em si, mas na relação que os sujeitos estabelecem com o mundo. 


\section{Resultados e discussões}

A escola deveria ser por excelência um espaço para a construção dos saberes, respeitando o ritmo de aprendizagem de cada aluno, proporcionando seu desenvolvimento. Entretanto, a escola hoje, aos moldes do modelo de homogeneização do ensino, acaba deixando de ofertar um ensino de qualidade para aqueles que não se encaixam no modelo de "aluno ideal". A falta de condições estruturais e pedagógicas, como a pouca oferta de materiais adaptados e o reduzido horário de planejamento docente, aliada a falta de continuidade na formação continuada acabam por afetar diretamente a qualidade do ensino nas escolas. Ao pensar o modelo escolar, Patto (1984) adverte que a escola, por sua vez, exprime os mecanismos sociais e reproduz em suas práticas escolares, que, no Brasil, são extremamente marcadas pelas desigualdades e acabam sendo naturalizadas e interiorizadas por aqueles que estão na escola.

A importância da formação de conceitos no processo de escolarização de alunos com deficiência intelectual já vem sendo discutido por Padilha (2002, 2007), Pletsch (2008, 2011, 2014), Braun (2012), Pletsch e Mendes (2014), Braun e Nunes (2015), Oliveira (2015), Oliveira et al (2015), Almeida (2016), Campos (2016), Mendes, R. (2016), Silva, C. (2016), entre outros, que apontaram para a necessidade de práticas pedagógicas que favoreçam a apropriação de conceitos científicos, articulados com as demandas culturais dos sujeitos e o contexto social em que estão inseridos.

Na aplicação da prova foi apresentado, para André, as dezesseis imagens de animais que representam diferentes categorias presentes na classificação: peixes, anfíbios, répteis, aves e mamíferos, explicando ao aluno que realizaria atividades com elas. Com o início da intervenção foi proposto que o aluno determinasse o significado de cada imagem e posteriormente que ele compare as imagens do leão e do tigre, traçando semelhanças e diferenças. Por fim, foi solicitado que o aluno agrupe as imagens, de tal forma que as organizasse de maneira conceitual. A primeira figura foi posta sobre a mesa, iniciando a primeira etapa: o método de determinação de conceitos. O aluno prontamente a segura e diz "uuraavo". E o diálogo se inicia com a mediação:

Pesquisadora: "uuraavo" é Sapo?

André: É.

Pesquisadora: Ah! É um sapo. Coloca aqui o sapo.

André: É. (estendendo o braço direito ele coloca a figura sobre a mesa)

Pesquisadora: Tem mais, olha só. O que é isso? 
André: (segurando a figura ele diz) - "poogo" (emite em som anasalado)

Pesquisadora: é o quê?

André: “poogo". (vira-se e emite o som onomatopaico característico do porco) - "oin”, "oin”.

Pesquisadora: É o porco?

André: É (estendendo o braço direito ele coloca a figura sobre a mesa)

Pesquisadora: Olha só. E esse aqui, o que é isto?

André: (segurando a figura ele diz) - "moooi", "ata"

Pesquisadora: Um boi?

André: "ata"

Pesquisadora: A vaca?

André: É. (voltando-se para ela e apontando a figura e emite o som onomatopaico característico da vaca) - "muuuuuú"

Pesquisadora: O que é este?

André: (já segurando a figura e olhando-a ele diz) - "au”, “au”.

Pesquisadora: É o “au” “au”?

André: É. Pesquisadora: “au au” é um?

Aluno: "uuta".

Pesquisadora: Como é que é?

Aluno: (virando e desvirando figura, ele repete) "au", "au".

A pergunta "O que é isso?" tinha o objetivo de compreender como ocorre a formação de conceitos pelo aluno. A partir do diálogo inicial, evidenciamos que André, ao nomear os animais, se reporta às suas vivências, enlaces imediatos e ao concreto, ou seja, ao que ele experiência na sua vida que independe da escolarização formal. $\mathrm{O}$ aluno caracteriza os animais pelo que Vigotski chamou de conceitos cotidianos, quando se refere aos mesmos pelo som que emitem: "oin, oin”, “muuuuuú", “au, au”, sinalizando o porco, a vaca e o cachorro. André tem a fala prejudicada, emite sons onomatopaicos, o que compromete em parte a expressão das suas ideias. Mesmo quando ele os nomeia "uuraavo", "poogo", "ata", referindo-se ao sapo, porco e vaca, ele fica na referência objetal, designando um objeto, ação ou característica (LURIA, 1986). Com relação ao desenvolvimento da formação de conceitos, Vigotski esclarece que: Embora os conceitos científicos e espontâneos se desenvolvam em direções opostas, os dois processos estão intimamente relacionados. É preciso que o desenvolvimento de um conceito espontâneo tenha alcançado um certo nível para que a criança possa absorver um conceito científico correlato. Por 
exemplo, os conceitos históricos só podem começar a se desenvolver quando o conceito cotidiano que a criança tem do passado estiver suficientemente diferenciado - quando a sua própria vida e a vida dos que a cercam puder adaptar-se à generalização elementar (VIGOTSKI, 2011, p. 135).

Nessa direção, baseado em Vigotski, compreendemos que a maioria das respostas de André demostra seus conhecimentos cotidianos e encontra-se na fase do pensamento por complexos, porque ele nomeia os animais com base em características concretas. De acordo com Cenci (2011, p. 50), “essas generalizações são guiadas pela linguagem dos adultos, assim a criança utiliza as mesmas palavras e estabelece a comunicação, no entanto, o sentido que a criança atribui ao significado convencional lhe é próprio”. Van Der Veer e Valsiner (2001) relacionaram o pensamento por complexos aos "nomes de família”, pois, embora os familiares possuam traços em comum, nem todos têm traços iguais, contudo, se reúnem em "famílias" e se relacionam reciprocamente. Vejamos o episódio de Júlio, ao determinar os conceitos nesta primeira fase da investigação. Selecionamos o trecho a seguir:

Pesquisadora: Mostrou ao aluno a imagem de uma vaca e perguntou: O que é isso?

Júlio: “vacaca". (vaca)

Pesquisadora: E esse aqui? Júlio: “au au”.

Pesquisadora: O cachorro é um? Júlio: "pato", "pato"...

Pesquisadora: Olha só o que tenho aqui. O que será isso aqui?

Júlio: "pexe". (peixe)

Pesquisadora: Um peixe, muito bom!

Pesquisadora: E esse aqui?

Júlio: "bobota".

Pesquisadora: Borboleta!

Pesquisadora: E esse aqui?

O aluno ficou pensativo "humm, ahhh".

Pesquisadora: Como é o nome dele?

Júlio: "bobota".

Ao ofertar as dezesseis imagens de animais para Júlio, com o mesmo objetivo exposto acima, percebemos que o educando, apesar de nomear alguns animais, com semelhante dificuldade na fala, reconhece o peixe e a borboleta, designado por ele respectivamente como 
"pexe" e "bobota". Em certos momentos, realiza sem consciência, como podemos ver no final do episódio, quando se refere ao jacaré como borboleta e "au au" para designar o pato. Recorrendo a Vigotski (2010), compreendemos que o aluno ainda agrupa os animais aleatoriamente de maneira desorganizada e instável, por vezes, pela tentativa e erro. Leontiev (2005) esclarece que para haver aprendizagem conceitual é necessário a organização do pensamento. Assim, o desenvolvimento cognitivo ocorre quando o educando se apropria dos recursos culturais na relação com o outro e com o meio social. Para Vigotski (1995), sem a capacidade de pensar conceitualmente é impossível a consciência do ser humano.

Em vista disso, entendemos que o professor e a escola têm um papel substancial neste processo. Nas palavras de Leontiev: Podemos compreender de forma adequada o papel condutor da educação e da criação, operando precisamente em sua atividade e em sua atitude diante da realidade, e delimitando, portanto, sua psique e sua consciência (LEONTIEV, 1988, p. 63). Luria (1986) esclarece que, por mais simples que possa parecer à primeira vista, a referência objetal é produto de um longo desenvolvimento. André e Júlio estão na primeira etapa, em que a palavra "está entrelaçada com a situação, o gesto, a mímica, a entonação e somente nestas condições adquire a referência objetal" (LURIA, 1986, p .50). De acordo com o autor, essa referência tem início nos dois primeiros anos de vida, e, por volta dos três a cinco anos de idade, a criança já sabe o que é um "gato", um "peixe” e um "galo". Entretanto, ressalta que o caminho percorrido até as relações lógico-verbais, transitando do conceito cotidiano para o científico, "só ocorre com a educação", quando a palavra adquire sua função generalizadora e analítica (p. 59). Podemos assim dizer que, André e Júlio estão no processo entre os enlaces imediatos e a introdução do objeto, em um sistema de categorias, predominando o conteúdo real imediato da palavra. Na etapa que segue, método de comparação e diferenciação, são apresentadas duas imagens aos alunos e pedido que digam o que há de comum entre as figuras de animais e, posteriormente, o que há de diferente. Vejamos o episódio de André quando a pesquisadora coloca a imagem do leão e do tigre sobre a mesa e pergunta o que tem de parecido entre eles:

André: "rião".

Pesquisadora: É um leão ou um tigre?

André: É.

Pesquisadora: É igual a esse aqui? (a pesquisadora pega a figura do leão mostra pra ele e pergunta novamente)

Pesquisadora: O que eles têm de parecido? 
André: “oieesi”. (aponta para o elefante em seguida para o tigre) logo depois o aluno se dirige à pesquisadora e com a mão direita fazendo um gesto faz um som onomatopeico do leão "ahaaaaa".

A pesquisadora mostra a imagem da tartaruga e do peixe.

Pesquisadora: E esse aqui, olha. Que bichos são esses?

André: "uuunda".

Pesquisadora: Como?

André: "uuunda".

Pesquisadora: Tartaruga esse aqui?

André: É. O aluno arruma as figuras sobre a mesa.

Pesquisadora: Está arrumando? O que tem de diferente entre eles?

André não responde.

Nesta etapa, André ainda não construiu a capacidade de diferenciar uma categoria da outra de forma oralizada. Ao ser indagado sobre as semelhanças, o aluno tenta nomear alguns animais como o leão, chamado por ele de "riião" e a tartaruga nomeada de "uuunda". Durante a mediação, a pesquisadora mostra a imagem dos animais para atingir o objetivo desta etapa. Nessa direção Pimentel (2012, p.47) explica que "os procedimentos de mediação na escola (demonstração, assistência, fornecimento de pistas e instruções) são fundamentais para promover um ensino inclusivo capaz de favorecer o desenvolvimento". Entretanto, o aluno ainda não consegue traçar as diferenças e semelhanças entre os animais. Ele responde "oieesi" de maneira não compreensível e, em seguida, faz uma mímica e o som do leão, “ahaaaaa”. Podemos inferir a partir de Vigotski (2010), que André, nesta etapa, está na fase de amontados, produzindo as respostas por tentativa e erro e seguindo suposições. Seguindo os preceitos de Luria (1986) o aluno não separa os traços concretos e ainda não consegue introduzir os animais em uma categoria abstrata. Vejamos o que o referido autor diz a respeito: Pode se observar que nos pré-escolares o predomínio absoluto não é da operação do descobrimento das semelhanças, mas sim da operação de diferenciação, do assinalamento dos traços imediatos que diferenciam os dois objetos nomeados (LURIA, 1986, p.63).

Como podemos ver, dada esta situação, André ainda não desenvolveu a capacidade de inserir os animais em uma situação imediata, nem separar os traços concretos, como tão pouco consegue conceituar na categoria animais. Situação semelhante ocorre com Júlio, quando a 
pesquisadora passa para a mesma etapa, ao comparar as semelhanças entre os animais. Júlio coloca a figura do cachorro e do gato sobre a mesa e prossegue a mediação:

Pesquisadora: Olha só! Esse aqui quem é?

Júlio: "atchot", "atchot". (gato)

Pesquisadora: E esse aqui quem é?

Júlio: "autchoca". (cachorro)

A pesquisadora aponta para a figura do cachorro e do gato novamente.

Pesquisadora: Esse aqui é igual a esse?

O aluno fica observando e mexe nas figuras, olha para o gato e diz: "atchot". Pesquisadora: O que o gato tem igual ao cachorro?

Júlio: "atchot". (gato)

Pesquisadora: $\mathrm{O}$ que tem de igual entre o cachorro e o gato?

Júlio: A pata.

Pesquisadora: A pata?

Júlio: "Ábabababa”.

Ele continuava a olhar para o cachorro e diz: "Ococo".

Júlio ao tentar traças as semelhanças entre os animais ofertados pela pesquisadora consegue apenas nomeá-los de maneira quase incompreensível. Ao falar "atchot" ele aponta para a imagem do gato, e ao dizer "autchoca" ele sinaliza em direção a imagem do cachorro. Em um momento, ele responde que a semelhança entre os animais está na pata, mas não prossegue. Luria (1986) esclarece que nesta etapa, espera-se que o sujeito consiga, sem dificuldades, dar uma resposta categorial como, o gato e o cachorro são animais, ou ainda, o gato e o cachorro são animais domésticos. A tarefa de comparar estes objetos e inseri-los em uma categoria é fácil (LURIA, 1986, p. 61), entretanto, para eles ainda não foi tarefa possível, pois a capacidade de análise, separar os traços generalizando-os, ainda não foram desenvolvidas. Remetendo aos preceitos de Vigotski (2010) podemos dizer que o educando ainda se encontra na fase de amontoados, porque, embora, reconheça o gato e o cachorro, os critérios de seleção não são coerentes, apresentando instabilidade na organização do pensamento. Ademais, a elaboração conceitual depende da escolarização ofertadas e as atividades dirigidas, que implicará diretamente na capacidade da formação de conceitos (LURIA, 2010). Para Braun e Nunes (2015, p.89), diante da formação de conceitos em pessoas com deficiência intelectual, o desafio consiste 
em "conhecermos as possibilidades para o aluno conservar as informações e conhecimentos adquiridos, para seguir adiante". No episódio de André, a pesquisadora ofertou a imagem do gato e do cachorro e solicitou que o aluno estabelecesse as diferenças entre os animais. Vejamos:

Pesquisadora: E esse aqui é o? (ela coloca as figuras do cachorro e do gato lado a lado)

André: “aatú”. (gato)

Pesquisadora: O que ele tem de diferente o gato do cachorro?

André: "au" "au" "ava".

Pesquisadora: Muito bem! Este é o latido do cachorro.

Pesquisadora: O que você acha que tem de diferente no cachorro e no gato?

André: "miau".

André mais uma vez nomeia os amimais de maneira quase incompreensível, designando o gato por "aatú" e depois pelos sons que o cachorro e o gato emitem. O aluno estabelece as diferenças implicitamente quando a pesquisadora pergunta em dois momentos: O que ele tem de diferente o gato do cachorro? Ele primeiro diz "au au" e, no segundo momento, quando indagado, ele responde "miau". Percebemos que, na sua maneira, ele diz que a diferença é que o cachorro late e o gato mia. Diante dessas considerações e das reflexões à luz de Vigotski (2010) compreendemos que o aluno mostrou seus conhecimentos cotidianos e encontra-se na fase do pensamento por complexo. Hostins e Jordão $(2014$, p.10) ao analisarem esta fase esclarecem que a tendência é que a criança elabore o pensamento a partir "dos enlaces reais imediatos, vinculados as experiências imediatamente vivenciadas, $e$ por assim o ser são sempre temporários, focalizados no objeto e no cotidiano”.

André descreve o som dos animais, separando os traços concretos do cachorro e do gato, não introduz os animais em uma categoria abstrata ficando na interação concreta, em suas experiências adquiridas no meio cultural, porque ele teve a experiência de ver o cachorro latindo e o gato miando (LURIA, 1986, p. 62). Pinto e Góes (2006, p.16) esclarecem que para que os alunos com deficiência intelectual atinjam formas mais elaboradas de pensamento são necessárias "a plasticidade de funcionamento e mediação social" para que a atuação não seja apenas nas suas experiências cotidianas. Conforme esclarece Braun e Nunes (2015) para que esta capacidade seja atingida é necessário que haja qualidade na oferta de atividades para alunos com deficiência intelectual, ou seja, propor atividades que possibilitem ao aluno adquirir 
conhecimento e formar conceitos demanda atenção à forma como este elabora e estrutura seu pensamento.

Neste processo, o professor se adianta ao modo de pensamento do aluno, desafiando-o com situações de ensino que o façam elaborar conceitos, em um grau de complexidade gradativo, impulsionando seu desenvolvimento (BRAUN; NUNES, 2015, p. 76). Luria ao analisar a capacidade de comparar e diferenciar esclarece que a capacidade de diferenciação é desenvolvida primeiro que a capacidade de comparar. Em estudantes iniciantes quando se pergunta o que há de comum entre o cachorro e o gato ou entre a bicicleta e a motocicleta, ao invés de assinalar o que é geral a ambos os objetos, as crianças habitualmente assinalam a sua diferença. "A capacidade de diferenciação amadurece antes da capacidade de generalização" (LURIA ,1986, p.63).

Estas capacidades estão em construção para André e Júlio, uma vez que, André diferencia de forma não intencional e Júlio ainda está por alcançar este objetivo. Apesar de terem reconhecido, seja por nome, seja por som, cada animal caracterizado nas imagens, os alunos não terminam todo o teste, Júlio não consegue realizar o segundo momento do método de comparação e diferenciação, quando é convidado a traçar as diferenças entre os animais, que, para Luria (1986), esta capacidade amadurece mais rápido que a capacidade de comparar.

A classificação livre, última etapa, quando os alunos deveriam separar os animais em grupos de maneira conceitual, com um raciocínio mais elaborado, não foi realizada por ambos, devido às dificuldades que apresentaram nas etapas iniciais, que utilizam um raciocínio simples e menos complexo. A esse respeito, Oliveira et al (2015) nos esclarecem que a apropriação de conceitos científicos está relacionada com a aprendizagem dos conceitos cotidianos. Em suas palavras:

Muitas vezes, deparamo-nos com crianças que não se apropriaram de conceitos científicos, por exemplo, de tempo (ontem, hoje, amanhã) isso ocorre porque elas precisam aprender antes disso os conceitos cotidianos (antes, agora e depois) pois estes estão relacionados aos primeiros de maneira intrínseca (OLIVEIRA et al, 2015, p. 61).

A partir dos resultados das provas de Luria evidenciamos entraves e possibilidades para a elaboração de conceitos por alunos com deficiência intelectual e a importância da mediação pedagógica na formação de conceitos. Conforme analisou Abreu (2006) a formação de conceitos é um processo evolutivo, considerando sempre a importância da medição de alguém mais capaz que, na maioria das vezes, é o professor. É preciso refletir de que forma os conceitos científicos estão sendo ensinados nas escolas, porque a memorização, repetição e treinamento nos remetem 
a uma concepção de ensino do século passado que entende que o conhecimento é acabado e necessita apenas ser transmitido para o aluno.

Ademais, ensinar é partilhar conhecimento através do diálogo e da escuta e possibilitar que os alunos se apropriem dos saberes produzidos culturalmente. Apontamos algumas fragilidades na escolarização de pessoas com deficiência intelectual, mas também temos possibilidades, desde que sejam ofertadas práticas pedagógicas que favoreçam a apropriação de conceitos científicos articulados com as demandas culturais dos sujeitos. A capacidade de elaborar conceitualmente o pensamento, torna o indivíduo capaz de se relacionar com o mundo e com seus pares e interpretar a realidade que o cerca. Em indivíduos com deficiência intelectual esse postulado é sinônimo de desenvolvimento escolar e inclusão social.

\section{Referências bibliográficas}

ABREU, M. C. B. F. de. Desenvolvimento de conceitos científicos em crianças com deficiência mental. 113f. Dissertação (Mestrado). Programa de Mestrado em Psicologia, Universidade Católica de Brasília, 2006.

ALMEIDA, T. F. de. Análise dos indicadores e políticas de inclusão escolar na Baixada Fluminense. 147f. Dissertação (Mestrado em Educação), Curso de Pós-Graduação em Educação, Contextos Contemporâneos e Demandas Populares (PPGEDUC), Universidade Federal Rural do Rio de Janeiro, Nova Iguaçu, RJ. 2016.

BRAUN, P. NUNES, L.R.O de P. A Formação de Conceitos em Alunos com Deficiência Intelectual: o Caso de Ian. Revista Brasileira de Educação Especial, Marília, v.21, n.1, p.75-92, jan./maio, 2015.

BRAUN, P. Uma intervenção colaborativa sobre os processos de ensino e aprendizagem do aluno com deficiência intelectual. 324f. Tese 116 (Doutorado em Educação), Universidade do Estado do Rio de Janeiro. Rio de Janeiro, 2012.

CAMPOS, E. C. V. Z. Diálogos entre o currículo e o planejamento educacional individualizado (PEI) na escolarização de alunos com deficiência intelectual. 173f. Dissertação (Mestrado em Educação) Universidade Federal Rural do Rio de Janeiro. Rio de janeiro. 2016.

CENCI, A. Processos mediativos e formação de conceitos cotidianos: implicações nas dificuldades de aprendizagens. 164f. (Mestrado) em Educação Especial. Universidade Federal de Santa Maria. Rio Grande do Sul, 2011.

CORRÊA, R, P; MORAES, L, H. A construção dos processos psicológicos superiores e a elaboração conceitual em alunos com deficiência intelectual: Um olhar sobre o trabalho docente In: PLETSCH, M.D; SOUZA, F.F (organizadoras) Observatório de Educação Especial e 
Inclusão Escolar: Balanço das pesquisas e das prática na Baixada Fluminense. São Carlos, São Paulo: Marquezine \& Manzini, ABPPE, 2015.

FRIEDRICH, J. Lev Vigotski: mediação, aprendizagem e desenvolvimento; uma leitura filosófica e epistemológica. Tradução Anna Rachel Machado e Eliane Gouvêa Lousada.

Campinas, São Paulo: Mercado das Letras, 2012.

HOSTINS, R. C. L., \& JORDÃO, S. G. F. Política de inclusão escolar e práticas curriculares de elaboração conceitual de alunos público-alvo da Educação Especial. Arquivos Analíticos de Políticas Educativas, 23(28). Dossiê Educação Especial: Diferenças, Currículo e Processos de Ensino e Aprendizagem II. Editoras convidadas: Márcia Denise Pletsch \& Geovana Mendonça Lunardi Mendes. 2014.

LEONTIEV, A. N. Os princípios do desenvolvimento mental e o problema do atraso mental. In: LURIA, A. R. et al. (Org.). Psicologia e pedagogia: bases psicológicas da aprendizagem. São Paulo: Centauro, 2005. p.87-106.

Uma contribuição à teoria do desenvolvimento infantil. In: VIGOTSKI, L.; LURIA, A. R.; LEONTIEV, A. Linguagem, desenvolvimento e aprendizagem. São Paulo: Ícone/Edusp, 1988.

LURIA, A. R. Pensamento e Linguagem: as últimas conferências de Luria. Tradução de Diana Myriam Lichtenstein e Mário Corso. Porto Alegre: Artes Médicas, 1986.

MENDES, R. da S. A escolarização de alunos com deficiência intelectual no ensino fundamental da rede de ensino de Itajaí - SC.128f. Dissertação (Mestrado) Universidade do Vale do Itajaí. Itajaí, Santa Catarina, 2016.

MONTEIRO, A.; PLETSCH, M.D. Panorama da Educação Especial na Rede Municipal de Ensino de Belford Roxo. I Seminário Internacional de Inclusão Escolar: Práticas em Diálogo. Universidade do Estado do Rio de Janeiro - CAP, 21 a 23 de outubro. 2014. Disponível em: http://www.cap.uerj.br/site/images/stories/noticias/38-monteiro_e_pletsch.pdf. Acesso em setembro de 2017.

OLIVEIRA, M.C.P. de. A escolarização de alunos com deficiência intelectual à luz da perspectiva histórico-cultural: avaliação mediada e apropriação cultural. 133p. Dissertação (Mestrado) Universidade Federal Rural do Rio de Janeiro. Rio de Janeiro, 2015.

OLIVEIRA, M; ARAÚJO, D; LIMA, M. PLETSCH, M. Elaboração e Apropriação Conceitual na Escolarização de Alunos com Deficiência Intelectual. p.55.70. In: PLETSCH, M; LUNARDI, G.M; HONSTINS, R.C.L. (org) A escolarização de Alunos com deficiência intelectual: políticas, práticas e processos cognitivos. São Carlos: Marquezine \& Manzini: ABPPE, 2015.

PADILHA, A M.L. Práticas Pedagógicas na Educação Especial - a capacidade de significaro mundo e a inserção cultural do deficiente mental. Campinas, SP: Autores Associados, 2001.

Elaboração Conceitual: papel fundamental da escola. Revista ACTA Científica, v. 2, n.3. Engenheiro Coelho: Imprensa Universitária Adventista, 2002, pp.6-12. 
PATTO, M.H.S. Psicologia e ideologia: uma introdução crítica a psicologia escolar. São Paulo: TA Queiroz, 1984.

PIMENTEL, S. C. Conviver com a Síndrome de Down em escola inclusiva: mediação pedagógica e formação de conceitos. Rio de Janeiro: Vozes, 2012.

PINO, A. O social e cultural na obra de Vygotsky. Educação e Sociedade, Campinas, vol. 21, n.71, pp. 45-78, 2000.

PINTO, G. U.; GÓES, M. C. R. de. Deficiência mental, imaginação e mediação social: um estudo sobre o brincar. Revista Brasileira de Educação Especial. Marília: ABPEE/FFC-UnespPublicações, v.12, n.1, p. 11-28, jan./abr.2006.

PLETSCH, M. D. A dialética da inclusãolexclusão nas políticas educacionais para pessoas com deficiências: um balanço do governo Lula (2003-2010). Revista Teias, v. 12, nº. 24, p.39-55, Rio de Janeiro, jan./abril de 2011.

Escolarização de alunos com deficiência intelectual no Brasil: da institucionalização às políticas de inclusão (1973-2014). Arquivos Analíticos de Políticas Educativas. Dossiê Educação Especial: diferenças, currículo e processos de ensino e aprendizagem, v. 22, n. 81, 2014.

PLETSCH, M. D.; BRAUN, P. A Inclusão de Pessoas com Deficiência Mental: um Processo em Construção. Democratizar, v .II, n .2, mai /ago, 2008.

PLETSCH, M. D.; MENDES, G. M. L. unardi. Perspectivas sobre políticas e processos de ensino e aprendizagem. Arquivos Analíticos de Políticas Educativas, 22 (77). 2014. (Dossiê Educação Especial: diferenças, currículo e processos).

PLETSCH, M. D.; MENDES, G. M. L.. Perspectivas sobre políticas e processos de ensino e aprendizagem. Arquivos Analíticos de Políticas Educativas, 22 (77). 2014. (Dossiê Educação Especial: diferenças, currículo e processos).

PLETSCH, M.D.; MENDES, G.M.L.; HOSTINS,R.L. A escolarização de alunos com deficiência intelectual: políticas públicas, processos cognitivos e avaliação da aprendizagem. Projeto de Pesquisa OBEDUC / Capes. 2013-2017.

SILVA, C. da. Elaboração conceitual no processo de escolarização de alunos com deficiência intelectual no município de Balneário Camboriú: estratégias e mediações na elaboração de conceitos. 132 f. Dissertação (Mestrado) Universidade do Vale do Itajaí. Itajaí, Santa Catarina, 2016.

VAN DER VEER, R.; VALSINER, J.. Vygotsky: uma síntese. São Paulo: Loyola, 2001.

VIGOTSKI, L. A Construção do Pensamento e da Linguagem. - São Paulo: Martins Fontes, 2000.

. Obras Escogidas, Vol. III. Madrid: Visor, 1995.

Pensamento e Linguagem. Trad. Paulo Bezerra. - São Paulo: Martins Fontes, 2010.

Revista Interinstitucional Artes de Educar. Rio de Janeiro, V. 4, N.1- pág. 157 - 173 - (jan. - abr. de 2018): "Questões contemporâneas sobre a Educação Especial na Perspectiva da Educação Inclusiva” - 
. A formação social da mente: o desenvolvimento dos processos psicológicos superiores. Organizadores Michael Cole (et al). Tradução José Cipolla Neto, Luís Silveira Menna Barreto, Solange Castro Afeche. $7^{a}$ edição. São Paulo: Martins Fontes, 2011.

YIN, R.K. Estudo de caso: planejamento e métodos. 3. ed. Porto Alegre: Bookman, 2005.

${ }^{\text {i }}$ Mestre pelo Mestrado Profissional em Diversidade e Inclusão pela Universidade Federal Fluminense (UFF). Professora da Rede Municipal de Educação do Rio de Janeiro. 